\title{
INFLUÊNCIA DO ESTRESSE CALÓRICO NA PRODUÇÃO E QUALIDADE DO LEITE
}

\author{
Influence of heat stress on milk yield and quality
}

\author{
Marco Aurélio de Felicio Porcionato ${ }^{[a]}$, Andrezza Maria Fernandes ${ }^{[b]}$, \\ Arlindo Saran Netto ${ }^{[\mathrm{c}]}$, Marcos Veiga dos Santos ${ }^{[\mathrm{d}]}$ \\ [a] Zootecnista, Pós-doutorando em Nutrição e Produção Animal da Faculdade de Medicina Veterinária e Zootecnia (FMVZ/ \\ USP), Pirassununga, SP - Brasil, e-mail: mafporcionato@usp.br \\ ${ }^{[b]}$ Médica Veterinária, Doutora, Docente do Departamento de Ciências Básicas da Faculdade de Medicina Veterinária e Zootecnia \\ (FZEA/USP), Pirassununga, SP - Brasil, e-mail: andrezzaf@usp.br \\ ${ }^{[c]}$ Zootecnista, Pós-doutorando em Zootecnia da Faculdade de Medicina Veterinária e Zootecnia (FZEA/USP), Pirassununga, \\ SP-Brasil, e-mail: saranetto@yahoo.com \\ ${ }^{[d]}$ Médico Veterinário, Doutor, Docente do Departamento de Nutrição e Produção Animal da Faculdade de Medicina Veterinária \\ e Zootecnia (FMVZ/USP), Pirassununga, SP - Brasil, e-mail: mveiga@usp.br
}

\begin{abstract}
Resumo
A nutrição, a sanidade, o manejo e a genética são fatores importantes em uma pecuária produtiva. Mas, em se tratando de manejo de bovinos leiteiros em condições de clima quente, como no Brasil, o estresse calórico pode influenciar negativamente o bem-estar e a produtividade dos animais. O estresse calórico, além de perdas econômicas diretas, afeta ainda o consumo de alimento, reduzindo a ingestão de matéria seca, com consequente diminuição da produção e qualidade do leite. Esse consumo irregular de alimento pode levar a um aumento do intervalo entre partos, atrasando o ciclo reprodutivo. Vacas mantidas em condições de altas temperaturas ambientais apresentam menor habilidade em defender-se de infecções bacterianas e outros patógenos. Contudo, estratégias de climatização, tais como sombreamentos, ventiladores e aspersores, podem proporcionar melhores condições aos animais, reduzindo os efeitos deletérios do estresse calórico.
\end{abstract}

Palavras-chave: Adaptação. Comportamento. Climatização. Termoneutralidade. Vaca leiteira.

\begin{abstract}
Nutrition, health, handling and genetics are important factors in cattle productive. But for handling dairy bovines in hot climate conditions, as in Brazil, caloric stress can negatively influence the animal's welfare and productivity. Caloric stress improve direct economic losses,
\end{abstract}

Rev. Acad., Ciênc. Agrár. Ambient., Curitiba, v. 7, n. 4, p. 483-490, out./dez. 2009 
still affects the food intake, reducing the dry matter intake, with consequent reduction of the quality and milk yield. This irregular food intake can take to an increase on the calves' intervals, slowing down the reproductive cycle. Cows kept in conditions of high ambient temperatures have less ability in defending of bacterial infections and other pathogens. However, acclimatization strategies such as shadow, ventilators and aspersers can provide better conditions to the animals, reducing the deleterious effect of the caloric stress.

Keywords: Adaptation. Behavior. Acclimatization. Thermoneutrality. Dairy cow.

\section{INTRODUÇÃO}

No Brasil, a temperatura média do ar está geralmente situada acima dos $20^{\circ} \mathrm{C}$, sendo que, nas horas mais quentes do dia, as temperaturas observadas permanecem acima $\operatorname{dos} 30^{\circ} \mathrm{C}$ em grande parte do ano, atingindo a faixa de $35^{\circ} \mathrm{C}$ a $38^{\circ} \mathrm{C}$ (TITTO, 1998).

O estresse calórico é um típico problema encontrado no manejo de vacas leiteiras nos trópicos e subtrópicos, causando reduções na produção e mudanças na composição do leite, redução na ingestão de alimentos e aumento na ingestão de água. A perda de produção de leite devido ao aumento de temperatura depende de fatores como a umidade relativa do ar, velocidade do vento, nutrição e outros fatores relacionados ao manejo. No entanto, são frequentemente observadas perdas produtivas de $10 \%$ ou mais (HEAD, 1995).

Há grande variação na literatura sobre as temperaturas críticas superior e inferior, que delimitam a faixa de termoneutralidade para animais, pois o conforto térmico depende também da umidade relativa do ar, da capacidade adaptativa do animal, do metabolismo e do período produtivo (TITTO, 1998).

A temperatura crítica superior para vacas das raças Pardo Suíço e Jersey em lactação pode chegar, respectivamente, a $27^{\circ} \mathrm{C}$ e $29^{\circ} \mathrm{C}$ (HAFEZ, 1975). De acordo com Nääs (1989), a faixa de $13^{\circ} \mathrm{C}$ a $18^{\circ} \mathrm{C}$ mostrou-se confortável para a maioria dos ruminantes, enquanto que para vacas em lactação o melhor intervalo estaria entre $4^{\circ} \mathrm{C}$ e $24^{\circ} \mathrm{C}$, podendo ser restringida entre $7^{\circ} \mathrm{C}$ e $21^{\circ} \mathrm{C}$ em função da umidade relativa do ar e radiação solar. Huber (1990) reportou a zona de termoneutralidade de $4^{\circ} \mathrm{C}$ a $26^{\circ} \mathrm{C}$, para vacas holandesas em lactação.

\section{Estresse calórico e produção de leite}

A homeotermia aparece como prioridade no metabolismo do animal frente a outras funções produtivas, como, por exemplo, a lactação (BACCARI JUNIOR, 2001). O estresse calórico pode resultar em um decréscimo de $17 \%$ na produção de leite de vacas de $15 \mathrm{~kg}$ de leite/ dia e de $22 \%$ em vacas de $40 \mathrm{~kg} /$ dia (PINARELLI, 2003).

A diminuição na produção de leite das vacas sob estresse térmico advindo de elevadas temperaturas deve-se, primordialmente, à redução no consumo de alimentos (McGUIRE, 1989; BACCARI JR., 2001), à hipofunção da tireóide e à energia despendida para eliminar o excesso de calor corporal. A redução no consumo de alimentos é maior quanto mais intenso o estresse térmico, e seria devido principalmente à inibição, pelo calor, do centro do apetite localizado no hipotálamo, resultante da hipertermia corporal (BACCARI JR., 2001).

Além da redução no consumo de alimentos, as respostas das vacas em lactação ao estresse térmico incluem: redução na produção e porcentagem de gordura no leite; redução no consumo de forragem como porcentagem do total de alimento, quando oferecida separadamente; aumento das necessidades de manutenção; diminuição da atividade, especialmente durante o dia; aumento da frequência respiratória e hipertermia (BACCARI JR., 2001).

Rev. Acad., Ciênc. Agrár. Ambient., Curitiba, v. 7, n. 4, p. 483-490, out./dez. 2009 
Deve-se considerar que, em condições de estresse calórico, ocorre também um aumento na ingestão de água (PERISSINOTTO et al., 2005). Além disso, na época do ano em que há abundância de chuvas a alimentação restringe-se à pastagem, que apresenta um maior teor de água em sua composição. Esses fatores somados podem provocar uma diluição dos sólidos totais do leite (HOLMES; WILSON, 1989).

Paralelamente à redução do consumo, há aumento do fluxo sanguíneo periférico para reduzir a temperatura corporal, ocasionando redução na absorção de nutrientes e na disponibilidade desses à glândula mamária (McGUIRE, 1989). Adicionalmente, nos períodos mais quentes do ano, as vacas holandesas utilizam mecanismos como redução no tempo de alimentação e ruminação, e aumento no tempo de ócio, provavelmente para diminuir a produção de calor metabólico excedente. O aumento do tempo de permanência em pé pode auxiliar na dissipação do calor, como tentativa dos animais em manter a homeotermia (PIRES et al., 2002).

Em resposta ao estresse calórico, podem ainda ocorrer alterações metabólicas. O aumento da frequência respiratória causa perda de $\mathrm{CO}_{2}$ através da respiração, reduzindo a produção de ácido carbônico no sangue. Há então, uma elevação do $\mathrm{pH}$ do plasma, o que ocasiona uma alcalose respiratória. Paralelamente, em função do menor consumo alimentar, menor motilidade estomacal e predileção por alimentos concentrados (menor calor de fermentação no rúmen), há uma redução do pH ruminal, que, eventualmente, pode levar a uma maior produção de ácido lático. O excesso de ácido lático poderia ser absorvido, determinando uma redução do $\mathrm{pH}$ sanguíneo e levando a uma acidose metabólica. Observou-se, portanto, que o animal durante o estresse térmico permanece em um constante desequilíbrio fisiológico, que pode também ser responsável por problemas de saúde relacionados à menor resistência imunológica (MACHADO, 1998).

A recuperação da produção de leite após o estresse calórico ocorre lentamente e em graus que variam com a intensidade e duração do estresse, além da fase da lactação, dentro dos limites fisiológicos da glândula mamária, podendo recuperar totalmente a produção normal ou até comprometer toda a lactação (TITTO, 1998).

Foi observada diminuição da produção de leite quando os animais foram submetidos à temperatura de $32^{\circ} \mathrm{C}$ e a UR variou de $20 \%$ para $45 \%$. Essa diferença de $25 \%$ na umidade inibe o resfriamento evaporativo em bovinos, resultando na elevação da temperatura retal, causando diminuição no consumo de alimento e, consequentemente, perdas na produção de leite (CAMPOS et al., 2002).

A utilização correta de instalações e equipamentos, como ventiladores e aspersores, para reduzir o estresse térmico por calor pode melhorar a produtividade dos animais (MARCHETO et al., 2002).

\section{Índice de temperatura e umidade (ITU) e a produção de leite}

Campos et al. (2002) propuseram um limite máximo de 75, para o índice de temperatura e umidade (ITU), visando ao conforto térmico do rebanho leiteiro da raça holandesa. Observaram que valores de ITU de 70 ou menos, não causaram nenhum desconforto térmico para vacas leiteiras. Entretanto, para valores de 75 ou mais, a produção de leite e ingestão de alimentos foi seriamente prejudicada.

De modo geral, bovinos de todas as idades mostraram algum sinal de desconforto térmico acentuado com ITU igual ou superior a 78, e esse desconforto se torna agudo à medida que o índice aumenta (CAMPOS et al., 2002).

Aguiar e Targa (2001), pesquisando a produção de leite de vacas holandesas em função da temperatura do ar e do ITU, concluíram que o estresse classificado como "brando" (temperatura do ar de $27^{\circ} \mathrm{C}$ ou pouco mais e ITU de 72 ou pouco mais) por um período de quatro horas por dia, durante cinco dias, causou declínio na produção de leite nas fases de termoneutralidade subsequentes. Por outro lado, a produção de leite aumentou nas fases em que as vacas estiveram sob condições de estresse térmico brando, após permanecerem em condições termoneutras, revelando uma capacidade de recuperação parcial ou total, contanto que as vacas tenham permanecido anteriormente alguns dias em condições de conforto térmico.

Rev. Acad., Ciênc. Agrár. Ambient., Curitiba, v. 7, n. 4, p. 483-490, out./dez. 2009 
Nos meses de janeiro a março e de novembro a dezembro a diminuição da produção de leite pode variar de 0,35 a $1,83 \mathrm{~kg} / \mathrm{vaca} /$ dia até 0,5 e $5,70 \mathrm{~kg} / \mathrm{vaca} /$ dia para animais com produções de 15 a $35 \mathrm{~kg} / \mathrm{vaca} / \mathrm{dia}$, respectivamente (CAMPOS et al., 2002).

As regiões sul e sudeste do Brasil apresentam várias regiões propícias para a produção de leite com animais da raça holandesa, considerando o ITU como referência de conforto, cujos valores não ultrapassam o limite crítico de 72. Entretanto, nas áreas de risco para o bom desempenho produtivo e reprodutivo de animais de alta produtividade, podem ser adotadas medidas adequadas para reduzir ou eliminar os efeitos do estresse calórico, de acordo com as condições específicas de cada propriedade. Estudos de viabilidade econômica devem ser feitos para apoiar as decisões de adoção de métodos mais apropriados e efetivos de controle do estresse térmico nas propriedades produtoras de leite (CAMPOS et al., 2002).

Em experimento considerando dois valores de ITU $(68 \pm 3,75$ e $78 \pm 3,23$ para primavera e verão, respectivamente), o índice foi negativamente correlacionado com a produção de leite ( $\mathrm{r}=$ $0,76)$ e ingestão de alimentos $(r=-0,24)$. Quando o valor de ITU aumentou de 68 para 78 , a produção de leite decresceu em $21 \%$ e a ingestão de matéria seca em 9,6\%. A produção de leite diminuiu em 0,41 $\mathrm{kg} / \mathrm{vaca} / \mathrm{dia}$ para cada ponto a mais no valor de ITU acima de 69 . Os teores de gordura $(3,24 \%$ e 3,58\%) e proteína do leite $(2,88 \%$ e 2,96\%) foram menores no verão (BOURAOUI et al., 2002).

\section{Influência do estresse calórico na composição do leite}

A composição do leite pode ser alterada pelo estresse calórico, com redução nos teores de gordura, proteína e cálcio (TITTO, 1998), lactose, ácido cítrico e potássio (HEAD, 1989). Os valores de sólidos totais (ST) do leite sofrem uma variação sazonal anual, aumentando durante o período de frio e diminuindo na época de calor e chuvas (PONSANO et al., 1999). De acordo com Coolier (1985), os sólidos não-gordurosos também são menores durante os meses quentes, devido principalmente à variação no conteúdo proteico do leite.

Os teores de gordura do leite diminuem quando as vacas são expostas a estresse calórico classificado como "severo". Os ácidos graxos de cadeia longa aumentam e os de cadeia curta diminuem (BERNABUCCI; CALAMARI, 1998). Uma possível explicação para os menores teores de gordura observados no leite de vacas em situações de estresse calórico seria a variação no consumo de forrageiras pelos animais. O menor consumo de volumosos provoca uma alteração na relação acetato/propionato, alterando assim a composição do leite (COOLIER, 1985).

$\mathrm{Na}$ maioria dos casos, a proteína do leite é negativamente afetada pelo estresse calórico, com decréscimo nos teores de caseína. Os íons cálcio, fósforo e magnésio geralmente diminuem, enquanto os níveis de cloro aumentam (BERNABUCCI; CALAMARI, 1998).

Pinarelli (2003) observou que, para vacas mantidas em baixas temperaturas, as médias dos teores de gordura, proteína e lactose foram de 3,47\%, 3,07\% e 5,08\% respectivamente; para vacas em temperatura intermediária foram de 3,46\%, 3,02\% e 5,06\% e de 3,17\%, 2,89\% e 5,01\% para vacas mantidas em altas temperaturas.

\section{Células somáticas relacionadas ao estresse calórico}

A mastite é definida como uma inflamação da glândula mamária, de origem predominantemente bacteriana (INTERNATIONAL DAIRY FEDERATION, 1987). Em processos infecciosos do tecido glandular, observa-se frequentemente um aumento na liberação de células de diversos tipos no leite, as quais podem ser enumeradas no produto através de técnicas de contagem de células somáticas (CCS) (FONSECA; SANTOS, 2000). As células somáticas estão presentes normalmente no leite e são constituídas, em sua grande maioria, por leucócitos, sobretudo neutrófilos, e células de descamação do epitélio secretor da glândula (BIBALKE, 1984; NICKERSON, 1994).

Rev. Acad., Ciênc. Agrár. Ambient., Curitiba, v. 7, n. 4, p. 483-490, out./dez. 2009 
A CCS é um fenômeno dinâmico, estando sujeita a variações significativas. O estágio de lactação, a idade da vaca, a estação do ano, o tamanho do rebanho, o nível de produção de leite e a presença de outras doenças são fatores que podem afetar a concentração de células somáticas no leite. Porém, o fator que exerce maior influência sobre o nível de células somáticas do leite é a infecção intramamária (PHILPOT; NICKERSON, 2002).

Observou-se no verão uma elevação na porcentagem de novas infecções na glândula mamária, o que pode indicar maior quantidade de bactérias presentes na superfície dos tetos e/ou menor resistência imunológica (MACHADO, 1998).

A influência da estação do ano sobre escores durante a lactação provavelmente não é causada por mudanças de temperatura e umidade, mas por exposição das extremidades dos tetos aos patógenos do ambiente, resultando em novas infecções. Não há evidências de que o estresse térmico aumente diretamente a CCS em glândulas saudáveis. A CCS menor no inverno e maior no verão coincide com a incidência de mastite clínica durante os meses de verão (HARMON, 1994).

$\mathrm{O}$ estresse de altas temperaturas e umidade pode aumentar a suscetibilidade a infecções, bem como aumentar o número de patógenos aos quais as vacas estão expostas. A taxa de infecções por patógenos ambientais foi maior no verão e coincidiu com o maior número de coliformes nas camas dos animais (SMITH et al., 1985). Hogan et al. (1989) também reportaram uma associação das taxas de mastite clínica com as contagens bacterianas nas camas dos animais.

Avaliando a influência de fatores de meio ambiente na variação mensal da composição e contagem de células somáticas do leite em rebanhos no Estado de Minas Gerais, verificou-se que os teores de gordura e proteína foram maiores nos meses de inverno e mais baixos nos meses de verão. Os escores de células somáticas cresceram de fevereiro a junho e decresceram até um mínimo em outubro. A influência do mês de controle sobre a variação dos escores, embora pequena, foi significativa ( $p<$ 0,001). As condições do ambiente que favorecem a menor contagem de células somáticas tendem a favorecer a maior produção de leite. Adicionalmente, no início e no fim da lactação as células estão concentradas em menor volume de leite (TEIXEIRA et al., 2003).

Para cabras da raça alpina com produção média de leite de $2,5 \mathrm{~kg} / \mathrm{dia}$, submetidas à termoneutralidade ou estresse térmico por 56 dias em câmara climática, foi constatada diminuição da produção de leite e da porcentagem de gordura, proteína, lactose e sólidos totais (BRASIL et al., 2000). Em ovelhas submetidas a três diferentes ambientes, com baixa ventilação $(1 \mathrm{~m} / \mathrm{s})$, ventilação moderada $(2 \mathrm{~m} / \mathrm{s})$ e com ventilação programada associada a $70 \%$ de umidade, observou-se menores teores de caseína no tratamento com baixa ventilação, comparado aos demais tratamentos (SEVI et al., 2003).

\section{Climatização para amenizar o estresse calórico}

A exposição crônica à radiação solar e a ambientes com alta temperatura e umidade devem ser reduzidas, proporcionando aos animais oportunidades adicionais para perder calor, como o oferecimento de sistemas de ventilação, aspersão e resfriamento evaporativo. Muitas dessas estratégias podem ser implantadas com poucos custos diretos, mas alternativas podem ainda ser aplicadas com base na produtividade do rebanho (HEAD, 1995).

Em estudo comparando diferentes instalações, observou-se que os valores da produção de leite apresentaram diferenças significativas, sendo que o tratamento associando sombra à ventilação e aspersão apresentou a melhor média para produção de leite $(20,53 \mathrm{~kg})$, seguido dos tratamentos sombra com ventilação $(19,19 \mathrm{~kg})$ e somente sombra (18,20 kg) (NÄ̈̈S; ARCARO JR., 2001).

Para vacas da raça Jersey, a climatização (ventilação + nebulização) dos galpões propiciou uma produção de leite 19\% maior que o grupo não climatizado (PINHEIRO et al., 2005). De acordo com Silva et al. (2002), o efeito do resfriamento do ambiente usando sistema de resfriamento adiabático evaporativo por nebulização na pré-ordenha melhora as condições de conforto térmico no curral de espera, refletindo em um aumento de $7,28 \%$ na produção de leite, além de promover redução na frequência respiratória e cardíaca.

Rev. Acad., Ciênc. Agrár. Ambient., Curitiba, v. 7, n. 4, p. 483-490, out./dez. 2009 
A aspersão utilizada em galpões tipo free stall pode proporcionar um aumento de $3 \%$ na produção de leite em relação à utilização de nebulização. Esse aumento representou, no rebanho estudado, por volta de 18 litros/vaca/mês. Esta diferença na produção, apesar de pouco significativa, representa um incremento de 5,8\% na receita mensal por animal (PERISSINOTTO et al., 2006).

Avaliando a eficiência da climatização da sala de espera, verificou-se que não houve diferença entre os tratamentos para a produção de leite. Todavia, os animais com sala de espera com ventilação apresentaram maior teor de gordura no leite e também apresentaram maiores concentrações hormonais de cortisol, $\mathrm{T}_{3}$ e $\mathrm{T}_{4}$, seguidos pelo tratamento sala de espera com ventilação artificial + aspersão. Concluiu-se a climatização com ventilação + aspersão proporcionou melhores condições de conforto aos animais, porém o tempo de permanência no local climatizado (30 minutos) foi, provavelmente, insuficiente para proporcionar aumentos na produção de leite (MATARAZZO et al., 2007).

\section{CONSIDERAÇÕES FINAIS}

Pode-se concluir que para cada situação há uma alternativa que se apresenta mais eficaz para amenizar os efeitos deletérios do estresse calórico sobre a produção e qualidade do leite e sobre o bemestar animal. Assim, devem-se adotar medidas visando ao conforto térmico, considerando as características climáticas inerentes a cada propriedade e à região na qual se localiza, além das características do rebanho e a relação custo-benefício.

\section{REFERÊNCIAS}

AGUIAR, I. S.; TARGA, L. A. Respostas termorreguladoras, armazenamento de calor corporal e produção de leite de vacas holandesas mantidas ao sol e com acesso à sombra natural. Revista Energia na Agricultura, Botucatu, v. 14, n. 4, p. 9-17, 2001.

BACCARI Jr., F. Manejo ambiental da vaca leiteira em climas quentes. Londrina, 2001.

BERNABUCCI, U; CALAMARI, L. Effects of heat stress on bovine milk yield and composition. Zootecnica e Nutrizione Animale, Bologna, v. 24, n. 6, p 247-257, 1998.

BIBALKE, D. The effect of high somatic cell count on the quality of dairy products. Dairy, Food and Environmental Sanitation, Ames, v. 4, p. 67-68, 1984.

BOURAOUI, R. et al. The relationship of temperature-humidity index with milk production of dairy cows in a Mediterranean climate. Animal Research, Paris, v. 51, n. 6, p. 479-491, 2002.

BRASIL, L. H. A. et al. Efeitos do estresse térmico sobre a produção, composição química do leite e respostas termorreguladoras de cabras da raça Alpina. Revista Brasileira de Zootecnia, Viçosa, v. 29, n. 6, p. 1632-1641, 2000.

CAMPOS, A. T. et al. Estudo do potencial de redução da temperatura do ar por meio do sistema de resfriamento adiabático evaporativo na região de Maringá-PR. Acta Scientiarum, Maringá, v. 24, n. 5, p. 1575-1581, 2002.

COOLIER, R. J. Nutritional, metabolic and environmental aspects of lactation. In: LARSON, B. L. (Ed.). Lactation. Iowa: State University Press, 1985. p. 80-128.

FONSECA, L. F. L.; SANTOS, M. V. Qualidade do leite e controle de mastite. São Paulo: Lemos, 2000.

HAFEZ, E. S. E. The behaviour of domestic animals. 2nd ed. London: Bailiere Tindal, 1975.

Rev. Acad., Ciênc. Agrár. Ambient., Curitiba, v. 7, n. 4, p. 483-490, out./dez. 2009 
HARMON, R. J. Symposium: mastitis and genetic evaluation for SCC - physiology of mastitis and factors affecting SCC. Journal of Dairy Science, Champaign, v. 77, n. 7, p. 2103-2112, 1994.

HEAD, H. H. The strategic use of the physiological potential of the dairy cow. In: SIMPÓSIO LEITE NOS TRÓPICOS: novas estratégias de produção, 1., 1989, Botucatu. Anais... Botucatu: UNESP, 1989. p. 38-89.

Management of dairy cattle in tropical and subtropical environments: improving production and reproduction. In: CONGRESSO BRASILEIRO DE BIOMETEOROLOGIA, 1., 1995, Jaboticabal. Anais... Jaboticabal: SBBiomet, 1995. p. 26-68.

HOGAN, J. S. et al. Bacterial counts in bedding materials used in nine commercial dairies. Journal of Dairy Science, Champaign, v. 72, n. 1, p. 250-258, 1989.

HOLMES, C. W.; WILSON, G. F. Produção de leite a pasto. Campinas: Instituto Campineiro de Ensino Agrícola, 1989.

HUBER, J. T. Alimentação de vacas de alta produção sob condições de estresse térmico. In: PEIXOTO, A. M. et al. Bovinocultura leiteira. Piracicaba: FEALQ, 1990. p. 33-48.

INTERNATIONAL DAIRY FEDERATION. Bovine mastitis: definition and guidelines for diagnosis. Bulletin of International Dairy Federation, v. 211, p. 7, 1987.

MACHADO, P. F. Efeitos da alta temperatura sobre a produção, reprodução e sanidade de bovinos leiteiros. In: SIMPÓSIO BRASILEIRO DE AMBIÊNCIA NA PRODUÇÃO DE LEITE, 1., 1998, Piracicaba. Anais... Piracicaba: FEALQ, 1998. p. 179-188.

MARCHETO, F. G. et al. Efeito das temperaturas de bulbo seco e de globo negro e do índice de temperatura e umidade, em vacas em produção alojadas em sistema de free-stall. Brazilian Journal of Veterinary Research and Animal Science, São Paulo, v. 39, n. 6, p. 320-323, 2002.

MATARAZZO, S. V. et al. Eficiência de sistemas de climatização na área de descanso em instalações do tipo free-stall e sua influência nas respostas produtivas e fisiológicas de vacas em lactação. Boletim de Indústria Animal, Nova Odessa, v. 64, n. 3, p. 221-232, 2007.

McGUIRE, M. A. et al. Effects of thermal stress and level of feed intake on portal plasma flow and net fluxes of metabolites in lactating cows. Journal of Animal Science, Champaign, v. 67, n. 4, p. 1050-1060, 1989.

NÄÄS, I. Princípios de conforto térmico na produção animal. São Paulo: Ícone, 1989.

NÄÄS, I.; ARCARO JR., I. Influência de ventilação e aspersão em sistemas de sombreamento artificial para vacas em lactação em condições de calor. Revista Brasileira de Engenharia Agrícola e Ambiental, v. 5, n. 1, p. 139-142, 2001.

NICKERSON, S. C. Bovine mammary gland: structure and function; relationship to milk production and immunity to mastitis. Agri-Practice, Santa Barbara, v. 15, n. 1, p. 11-18, 1994.

PERISSINOTTO, M. et al. Influência do ambiente na ingestão de água por vacas leiteiras. Revista Brasileira de Engenharia Agrícola e Ambiental, Campina Grande, v. 9, n. 2, p. 289-294, 2005.

PERISSINOTTO, M. et al. Eficiência econômica de sistemas de climatização em galpões tipo free stall, para o confinamento de bovinos leiteiros. Engenharia Rural, Piracicaba, v. 18, p. 59-63, 2006.

PINARELLI, C. The effect of heat stress on milk yield. Latte, Milan, v. 28, n. 12, p. 36-38, 2003.

PINHEIRO, M. G. et al. Efeito do ambiente pré-ordenha (sala de espera) sobre a temperatura da pele, a temperatura retal e a produção de leite de bovinos da raça Jersey. Revista Portuguesa de Zootecnia, Vila Real, v. 12, n. 2, p. 37-43, 2005. 
PHILPOT, W. N.; NICKERSON, S. C. Origem e significado das células somáticas: vencendo a luta contra a mastite. Naperville: Milkbizz, 2002.

PIRES, M. F. A. et al. Taxa de gestação de fêmeas da raça holandesa confinadas em free stall, no inverno e verão. Arquivo Brasileiro de Medicina Veterinária e Zootecnia, Belo Horizonte, v. 54, n. 1, p. 57-63, 2002.

PONSANO, E. H. G. et al. Variação sazonal e correlação entre propriedades do leite utilizadas na avaliação de qualidade. Revista Higiene Alimentar, São Paulo, v. 13, n. 64, p. 35-39, 1999.

SEVI, A. et al. Ventilation effects on air quality and on the yield and quality of ewe milk in winter. Journal of Dairy Science, Champaign, v. 86, n. 12, p. 3881-3890, 2003.

SILVA, I. J. O. et al. Efeitos da climatização do curral de espera na produção de leite de vacas holandesas. Revista Brasileira de Zootecnia, Viçosa, v. 31, n. 4, p. 2036-2042, 2002.

SMITH, K. L. et al. Environmental mastitis: cause, prevalence, prevention. Journal of Dairy Science, Champaign, v. 68, n. 6, p. 1531-1553, 1985.

TEIXEIRA, N. M. et al. Influência de fatores de meio ambiente na variação mensal da composição e contagem de células somáticas do leite em rebanhos no Estado de Minas Gerais. Arquivo Brasileiro de Medicina Veterinária e Zootecnia, Belo Horizonte, v. 55, n. 4, p. 491-499, 2003.

TITTO, E. A. L. 1998. Clima: influência na produção de leite. Ambiência na produção de leite em clima quente. In: SIMPÓSIO BRASILEIRO DE AMBIÊNCIA NA PRODUÇÃO DE LEITE, 1., 1998, Piracicaba. Anais... Piracicaba: FEALQ, 1998. p. 10-23. 